\title{
Effectiveness of depuration of Pacific Oyster (Crassostrea gigas): removal of bioaccumulated Vibrio vulnificus by UV-treatment
}

\author{
Heejin Jeong ${ }^{1}$ - Seul-Ki Park ${ }^{2}$ Du-Min Jo ${ }^{1}$ - Fazlurrahman Khan ${ }^{2}$ •

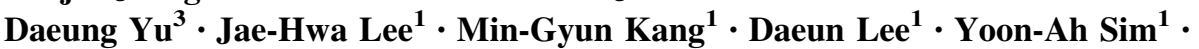 \\ Young-Mog Kim ${ }^{1}$
}

Received: 14 December 2020/Revised: 22 March 2021/Accepted: 20 April 2021/Published online: 15 May 2021

(C) The Korean Society of Food Science and Technology 2021

\begin{abstract}
The present study aimed to evaluate the efficacy of a depuration system equipped with UV-irradiation to control Vibrio vulnificus infection such as septicemia (or sepsis) using alive oysters. After $6 \mathrm{~h}$ of bioaccumulation of V. vulnificus, Pacific oyster Crassostrea gigas were found to be contaminated by $>8.0 \log$ MPN/g of $V$. vulnificus cells. After $60 \mathrm{~h}$ of depuration, the $V$. vulnificus cell number significantly decreased to $<4.0 \log \mathrm{MPN} / \mathrm{g}$. The present depuration process meets the standard effectiveness in reducing $V$. vulnificus cells by $>3.52 \log$ and $<30$ MPN/g as recommended by the National Shellfish Sanitization Procedure Molluscan Shellfish Control guidelines. Furthermore, no significant changes in $\mathrm{pH}$ value and glycogen content indicate that the depuration process did not affect the freshness and quality of the oyster samples. The present study could help control any potential infection
\end{abstract}

Heejin Jeong and Seul-Ki Park authors have equally contributed. associated with the consumption of raw oysters without losing their quality.

Keywords Depuration - Oyster · Most probable number . UV-treatment · Vibrio vulnificus

\section{Introduction}

Shellfishes mainly growing in the coastal areas are easily prone to microbial contamination by foodborne pathogens growing in various decomposed and fecal matters originated from residential areas, livestock farms, wildlife waste, and rainfall events (Oliveira et al., 2011). As a result of cultivation or harvesting the shellfish in the polluted region (polluted by partially treated or non-treated human effluent), there is a high risk of contamination by several pathogenic microbes (Copat et al., 2013). Consumption of microbially contaminated shellfish is known to be associated with many foodborne diseases. Due to the shellfish

Min-Gyun Kang

hghgh552@naver.com

Daeun Lee

say3455@naver.com

Yoon-Ah Sim

yoona7108@naver.com

1 Department of Food Science and Technology, Pukyong National University, Busan 48513, Republic of Korea

2 Institute of Food Science, Pukyong National University, Busan 48513, Republic of Korea

3 Department of Food and Nutrition, Changwon National University, Changwon 51140, Republic of Korea 
filter feeder characteristic, there is a high chance of concentration of pathogenic microorganisms in their intestine (Lees et al., 2000). Furthermore, the traditional ways of raw oysters consumption can contribute to the major causes of foodborne diseases (Robert et al., 1997). Several strategies have been proposed to prevent the foodborne pathogenic infection by intake of microbially contaminated oysters such as (i) control of sanitation in the shellfish growing area as well as in the production stages as recommended by National Shellfish Sanitation Programs (NSSP), (ii) relaying contaminated shellfish in the clean area to meet guideline or regulation after harvesting (U.S. FDA., 2019), and (iii) depuration of contaminated shellfish using clean water (Lees et al., 2010). If the shellfish exceeds the reference values of microbial load, the natural relaying or depuration process would be carried out to fit the reference values (McLeod et al., 2017). Sterilized seawater has been widely used in many harvesting fields such as oysters and bivalves for depuration (Phuvasate et al., 2012).

Furthermore, NSSP recommends that fecal microorganisms such as coliform should not be detected in water used for depuration. And in the NSSP, for the validation of post-harvest processing, the initial reduction of Vibrio Vulnificus was recommended to be $3.52 \log$ and $30 \mathrm{MPN} / \mathrm{g}$ (NSSP, 2019). Thus, it is cleared that several countries have been reported to apply the depuration process for maintaining hygienically safe seafood products (Lee et al., 2008). However, in the Republic of Korea, there are no such specific regulations and guidelines systems available for the application of the relaying and depuration process of the microbially contaminated shellfish.

A variety of foodborne pathogenic bacteria are detected commonly from seafood or shellfish products; however, Vibrio vulnificus is one of the marine bacterium associated with foodborne diseases (Oliveira et al., 2011). This bacterium causes foodborne illnesses with symptoms such as vomiting, diarrhea, and abdominal pain resulting from eating contaminated fish or shellfish. Reports also showed that $V$. vulnificus infection often causes fatal diseases such as sepsis in those suffering from chronic liver disease or weak immune systems, or wounded skin. In severe $V$. vulnificus, sepsis cases might be lead to death (Horseman et al., 2011). Also, V. parahaemolyticus is less hazardous than $V$. vulnificus, because symptoms caused by $V$. parahaemolyticus are milder than V. vulnificus infection. Hence, to prevent the foodborne diseases associated with microbially contaminated oyster consumption, there is an urgent need to develop approaches or methods to reduce or depurate the oyster sample contaminated by $V$. vulnificus. Thupila et al. (2011) and various studies have used shellfish samples homogenized into minced or paste form to control and reduce microbiological contamination in shellfish.
However, minced or pasted oysters are not suitable as a model to evaluate the real behaviors of microbes in shellfish samples during the depuration process. Besides, few reports on the depuration of alive oysters samples were microbially contaminated, especially with $V$. vulnificus (Corrêa et al., 2007; Croci et al., 2002; Oh et al., 2012; Ramos et al., 2012). Therefore, the present study aims to develop a strategy of in vivo bioaccumulation of $V$. vulnificus in the live oyster samples and investigating the effectiveness of the depuration process equipped with ultraviolet (UV)-irradiation.

\section{Materials and methods}

\section{Bacterial cultures and mediums}

The bacterial strain used in this study was $V$. vulnificus KCCM 41665, obtained from the Korean Culture Center of Microorganisms (KCCM, Seoul, Korea). This strain was cultivated in Luria-Bertani (LB; Difco Laboratories Inc., Detroit, USA) broth supplemented with $1.5 \% \mathrm{NaCl}$ and 35 ${ }^{\circ} \mathrm{C}$ temperature for the growth.

\section{Bioaccumulation and depuration of oyster samples}

Alive Pacific oysters Crassostrea gigas were purchased from the aquaculture farm located at Tong-Yeong, Gyeong-sang-namdo, and the Republic of Korea. Oysters with a weight of $49.3 \pm 5.4 \mathrm{~g}$, length of $9.7 \pm 1.2 \mathrm{~cm}$, and a width of $4.9 \pm 2.4 \mathrm{~cm}$ were sampled from November 2018 to February 2019 and transported under keeping it at less than $10{ }^{\circ} \mathrm{C}$ within $4 \mathrm{~h}$. Oysters samples were washed briefly with tap water to remove mud from the shell and placed in a rectangular high-density polyethylene (HDPE) tank $(50 \times 55 \times 60 \mathrm{~cm})$ containing $100 \mathrm{~L}$ of artificial seawater (ASW; salinity, $35 \mathrm{psu}$ ). Sixty oysters were then placed in a perforated plastic basket placed in the tank $90 \mathrm{~mm}$ above from the bottom (Fig. 1). ASW was prepared by dissolving 1:1 (w/w) of KENT artificial salt (KENT Marine, CA, USA) and sea salt (Hanju Salt., Co., Ltd, Ulsan, Korea) in tap water. The tank's temperature was maintained at $15{ }^{\circ} \mathrm{C}$ for $14-16 \mathrm{~h}$ before contaminating it with $V$. vulnificus. This temperature was kept constant using a water cooler circulated with a flow of $8 \mathrm{~L} / \mathrm{min}$ using a pump. For the inoculation of $V$. vulnificus into the tank, 1 $\mathrm{L}$ of the pre-cultured medium was centrifuged at $10,000 \times \mathrm{g}$ for $30 \mathrm{~min}$ and removed supernatant. After that, the pellet was resuspension in $100 \mathrm{~mL}$ of artificial seawater, and inoculation was performed into the tank. Finally, $V$. vulnificus cell was inoculated into the tank with a final level of approximately $10^{6} \mathrm{CFU} / \mathrm{mL}$. The tank was 
equipped with a circulation pump, therefore, the inoculated V. vulnificus spread evenly.

The spray bar was used to keep dissolved oxygen (DO) levels to survive oysters and feed intake. After the bioaccumulation, oysters were removed from the tank and placed in the depuration tank containing $100 \mathrm{~L}$ of filtered and UV-sterilized ASW. In parallel, a similar experiment was imitated free from contamination with $V$. vulnificus as a control.

In the present study, the depuration process was carried out at a small-scale shellfish purification described by Food and Agriculture Organization (FAO) with a slight modification (Lee et al., 2008). ASW for depuration was recirculating with a flow rate of $8 \mathrm{~L} / \mathrm{min}$ to ensure sufficient DO level in the water as described above. The UV-sterilized systems consist of a UV-tube ( $\varnothing 4 \mathrm{~cm}$, length $35 \mathrm{~cm}$, thickness $0.2 \mathrm{~cm}$, HANJIN QUARTZ CO., Seoul, Korea) housed inside a quartz sleeve. Low-pressure mercury vapour UV-lamps (AS ONE Corporation, Osaka, Japan) produce $85 \%$ of their light in the UV-C range at $253.7 \mathrm{~nm}$, which was the wavelength at which the highest germicidal activity reported (Ashrae et al., 2016). The total dose of
UV irradiation applied for the irradiation was calculated to be $13.00 \mathrm{~mJ} / \mathrm{cm}^{2}$. The total dose of UV-lamp irradiation was calculated considering the light source value of $15.8 \mathrm{~mW}$, irradiation length is $2 \mathrm{~cm}$, and irradiation time is $3.29 \mathrm{~s}$. The irradiation time was calculated using the water flow rate $(8 \mathrm{~L} / \mathrm{min})$ and the area of the pipe including the UV-lamp $\left(439.6 \mathrm{~cm}^{3}\right)$. ASW is passed parallel to the tube within a jacket of stainless steel or polyvinyl chloride (PVC). The cell population of $V$. vulnificus in oysters was analyzed (detailed described below) during the bioaccumulation and depuration process.

\section{Microbiological analysis}

After the bioaccumulation and depuration process, harvested oysters were rinsed and then opened aseptically using a sterile oyster-shucking knife. Six oyster meats, each with $50 \mathrm{~g}$, were aseptically transferred to sterile bags containing $450 \mathrm{~mL}$ of $0.1 \mathrm{M}$ phosphate-buffered saline (PBS; pH 7.0 containing $2 \% \mathrm{NaCl}$ ). The homogenization of the oyster meat was carried out using a stomacher (Bag Mixer 400VW; Interscience Inc., Saint Nom, France) for
Fig. 1 Diagram of seawater flow through a loaded tank in a recirculation system.

(A) Surface view of recirculation system, (B) Innerview of the recirculation system, and (C) Real image of the recirculation system. The tank containing $100 \mathrm{~L}$ of seawater is the size of $50 \times 55 \times 60 \mathrm{~cm}$ (A, UV Lamp; B, water pumping motor; $\mathbf{C}$, water gauge; $\mathbf{D}$, valve for removal water; $\mathbf{E}$, power; F, spray bar; G, Oyster in basket)
(A)

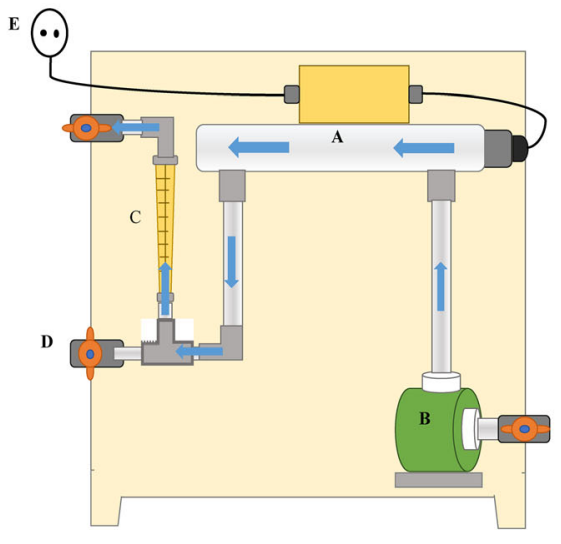

(B)

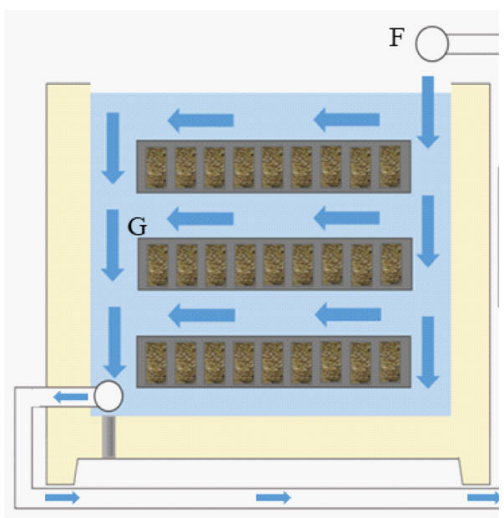

(C)

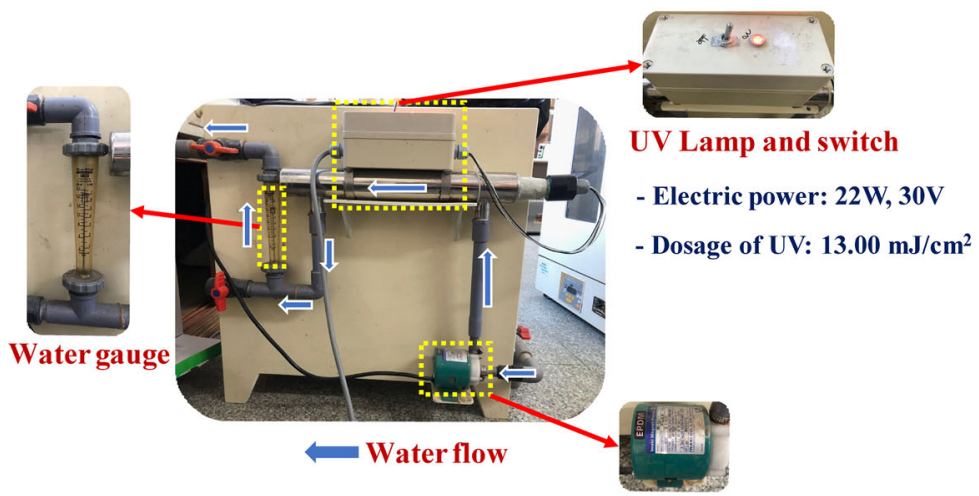

Motor for water circulation

- Model No.: MD-6Z

- Electric power: 32W, $220 \mathrm{~V}$

- Capacity: 8 L/min 
2 min. The viable cell count was determined by a standard plate count (SPC) method and the most probable number (MPN) method combined with polymerase chain reaction (PCR) (Luan et al., 2008). For determining the total viable cell count using the SPC method, the homogenized samples were serially diluted with $0.1 \mathrm{M}$ PBS and spread plated on LB-Na agar. All agar plates were incubated at $35{ }^{\circ} \mathrm{C}$ for 18 to $24 \mathrm{~h}$. Similarly, in the MPN-PCR method, the population of $V$. vulnificus in oysters was analyzed by a slightly modified method as reported in the Bacteriological Analytical Manual, U.S. Food and Drug Administration (Jang et al., 2018; U.S. FDA, 2019). The homogenized and serially diluted samples were individually inoculated into 3-tubes containing alkaline peptone water (APW; $\mathrm{pH} 8.4$, Difco Laboratories Inc.) and incubated at $35{ }^{\circ} \mathrm{C}$ for $12 \pm 2 \mathrm{~h}$. One loopful of enriched APW culture from a turbid tube was streaked onto individual thiosulfate citratebile salts-sucrose agar (TCBS; Difco Laboratories Inc.) for the detection of $V$. vulnificus colonies. All plates were incubated at $35{ }^{\circ} \mathrm{C}$ for $18-24 \mathrm{~h}$. Colonies that appeared round and green on TCBS were considered as positive for the $V$. vulnificus. Next, colony PCR was performed to identify $V$. vulnificus joyous bands, and the cell population of $V$. vulnificus was then determined using an MPN sheet (U.S. FDA, 2019). Primer designs and PCR conditions for specific $V$. vulnificus amplification were performed according to the previous report (Panicker et al., 2004). The specific primers were modified from $V$. vulnificus $v v h$ gene, which is as follows (Wang et al., 2003): sense: $5^{\prime}$ CAGCCGGACGTCGTCCATTTTG- ${ }^{\prime}$; antisense: $5^{\prime}$ ATGAGTAAGCGTC CGACGCGT-3'. PCR was performed at the condition as an initial denaturation at $94{ }^{\circ} \mathrm{C}$ for $5 \mathrm{~min}$, denaturation at $94{ }^{\circ} \mathrm{C}$ for $30 \mathrm{~s}$, annealing at $60{ }^{\circ} \mathrm{C}$ for $30 \mathrm{~s}$, elongation at $72{ }^{\circ} \mathrm{C}$ for $30 \mathrm{~s}$, and final elongation at $72{ }^{\circ} \mathrm{C}$ for $10 \mathrm{~min}$.

\section{Freshness analysis of oysters}

Shucked oysters were mixed and homogenized with distilled water at a ratio of 1:10 (w/v). The $\mathrm{pH}$ value was measured by $\mathrm{pH}$ meter (Orion 3 star; Thermo Scientific Inc., Fort Collins, CO). Glycogen content was determined according to the method described by Cicik and Engin (Cicik et al., 2005). Briefly, shucked oyster samples $(0.5 \mathrm{~g})$ were mixed with $5 \mathrm{~mL}$ of $30 \% \mathrm{KOH}$, sequentially boiled at $95{ }^{\circ} \mathrm{C}$ for $20 \mathrm{~min}$. After boiling, $0.5 \mathrm{~mL}$ of saturated $\mathrm{Na}_{2}$ $\mathrm{SO}_{4}$ solution and $5 \mathrm{~mL}$ of ethanol was added and boiled for $15 \mathrm{~min}$ at $95{ }^{\circ} \mathrm{C}$. After centrifugation $(1259 \times \mathrm{g}$ for $10 \mathrm{~min}$ ), the precipitate was added with $2 \mathrm{~mL}$ of deionized water and $2.5 \mathrm{~mL}$ of ethanol and further centrifuged at $1259 \times \mathrm{g}$ for $10 \mathrm{~min}$. Additionally, to completely dissolve the precipitate, $2 \mathrm{~mL}$ of $5 \mathrm{M} \mathrm{HCl}$ was added and eventually neutralized with $0.5 \mathrm{M} \mathrm{NaOH}$. The final neutralized samples $(10 \mathrm{~mL})$ were mixed with $5 \mathrm{~mL}$ of $0.2 \%$ anthronesulfate solution (Sigma-Aldrich, St. Louis, USA). The mixture was then heated at $95{ }^{\circ} \mathrm{C}$ for $10 \mathrm{~min}$, and the absorbance was measured at $620 \mathrm{~nm}$ using the spectrophotometer (UV mini-1240; Shimadzu, Tokyo, Japan). Glycogen content was determined by calibration curves using different concentration of glucose as the standard material and multiplied by the glycogen conversion factor of 0.9 .

\section{Statistical analysis}

All the experiments were performed in triplicates. Data were averaged, and the standard deviation was determined. Multiple comparisons were evaluated by two-way analysis of variance using SPSS ver. 25.0 statistical software (SPSS Inc., Chicago, USA). Significant differences between means were determined using Duncan's multiple range tests (Duncan et al., 1955). The statistical significance differences of each data were verified at a significance level of $5 \%(\mathrm{p}<0.05)$.

\section{Results and discussion}

\section{Preparation of alive oyster model samples bioaccumulated by $V$. vulnificus}

As shown in Fig. 2A, the cell populations of V. vulnificus bioaccumulated in the oysters rapidly increased and reached a maximum value of $>8.0 \log$ MPN/g after $6 \mathrm{~h}$, and this population level of the cell was found to be constant until $12 \mathrm{~h}$. There was no indigenous population of $V$. vulnificus in the collected samples of alive oysters before the start of bioaccumulation (Fig. 2B). Chae et al. (2009) reported that Vibrio spp. rarely can be detected in seawater, which was maintained below $15{ }^{\circ} \mathrm{C}$ temperatures. The collected oyster samples were not naturally contaminated by $V$. vulnificus since the seawater temperature was below $15{ }^{\circ} \mathrm{C}$ as observed during the harvesting season (average temperature was ranged in $8-10{ }^{\circ} \mathrm{C}$ from November 2018 to February 2019 in South Korea). Thus, V. vulnificus is successfully bioaccumulated inside the oyster, and the cell population tends to be maintained thereafter. These results were consistent with the previous reports that bacterial cells were accumulated in shellfish by the bioaccumulation process (Correa et al., 2007; Kwon et al., 2011). Dore et al. (1995) also reported that the initial bacterial population rapidly increased and was continuously maintained without employing the relaying or depuration process. 

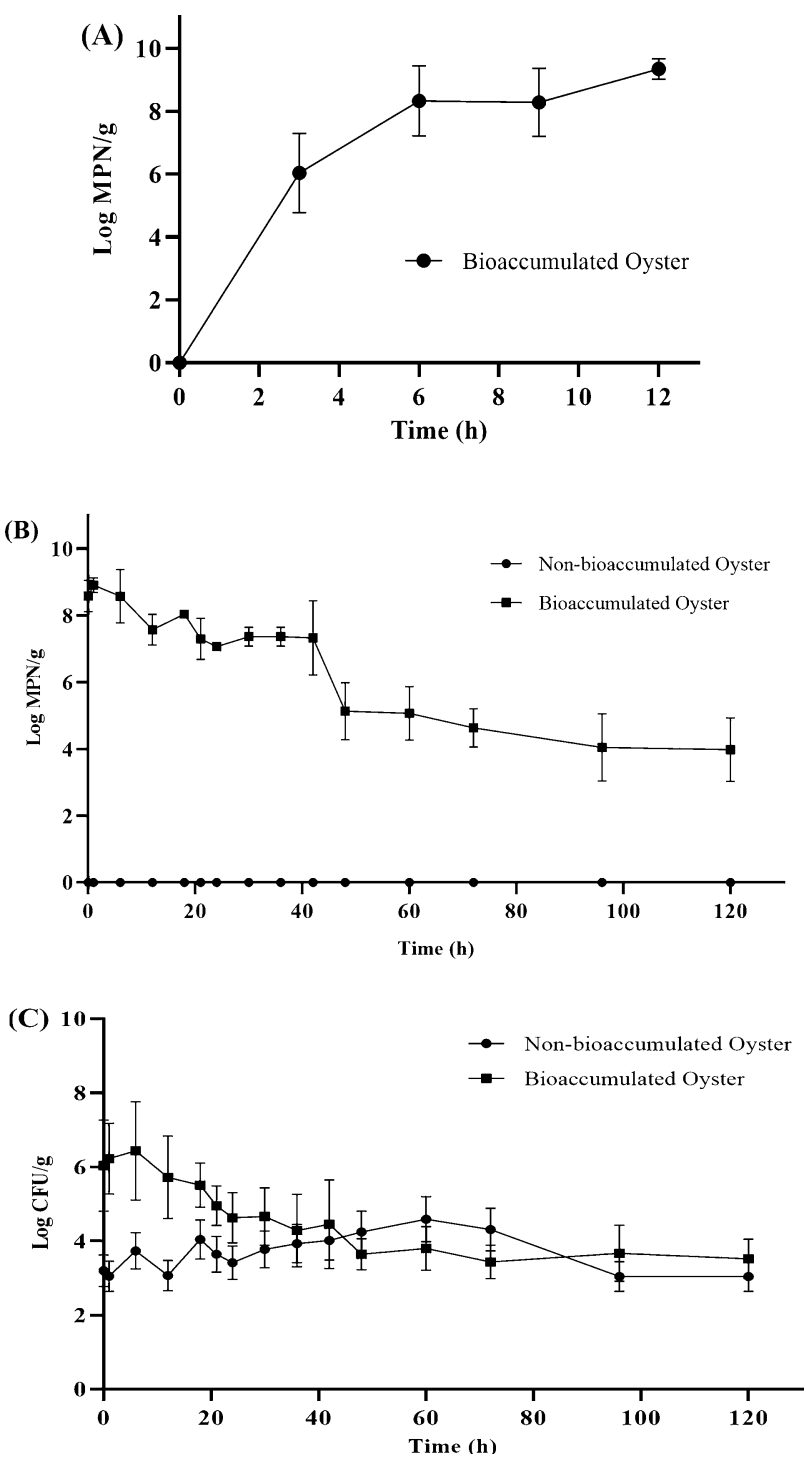

Fig. 2 Changes in viable cell count of Vibrio vulnificus in the oyster during bioaccumulation and depuration process. The oysters bioaccumulated in a water tank by inoculating $V$. vulnificus with a CFU value of $10^{6} \mathrm{CFU} / \mathrm{mL}$. (A) Bioaccumulation of oyster in the tank, (B) Change in viable cell count of Vibrio vulnificus (log MPN/g) during depuration, (C) Change in the total viable cell of Vibrio vulnificus count $(\log \mathrm{CFU} / \mathrm{g})$

\section{Reduction of bioaccumulated $V$. vulnificus by depuration equipped with UV- irradiation}

After $1 \mathrm{~h}$ of the depuration process, the viable cell count of $V$. vulnificus was found to be $8.91 \mathrm{log} \mathrm{MPN} / \mathrm{g}$ in the bioaccumulated oysters, and values were found to be significantly decreasing during the long period of the depuration process. After $60 \mathrm{~h}$ depuration, the viable cell count of $V$. vulnificus was reduced by $3.8 \mathrm{log} \mathrm{MPN} / \mathrm{g}$ in the bioaccumulated oysters (Fig. 2B). However, after $60 \mathrm{~h}$ depuration, a significant reduction of viable cell count has not occurred. According to the National Shellfish Sanitation Program (NSSP) guide for the Control of Molluscan Shellfish, the reduction of $>3.52 \mathrm{log}$ is an initial required value of post-harvest validation (NSSP, 2019). Thus, the reduction of viable cell count of $V$. vulnificus in the present study qualifies the standard guideline proposed by NSSP. The previous report showed that the UV-irradiation based depuration was effective in the reduction $(98 \%$ within $48 \mathrm{~h}$ ) of Escherichia coli from the bioaccumulated oysters and mussels (Dore et al., 1995). Besides, several studies also reported similar depuration effectiveness that can eliminate the harmful fecal bacteria such as E. coli, although less effective for Vibrio spp. (Croci et al., 2002; Sorio et al., 2017).

Previous reports showed that the total viable cell counts in bioaccumulated oysters decreased progressively during the depuration (Otwell et al., 2018). Hence, we also checked the total viable cell counts in the bioaccumulated oysters. The lowest viable cell count was observed after $72 \mathrm{~h}$ of depuration with a value of $3.43 \mathrm{log} \mathrm{CFU} / \mathrm{g}$ in bioaccumulated oyster samples (Fig. 2B). However, above $72 \mathrm{~h}$ of depuration, no significant changes were seen as the viable cell count range from 3.43 to $3.67 \mathrm{log} \mathrm{CFU} / \mathrm{g}$. A similar result was observed in the non-bioaccumulated oyster with total viable cell counts range from 3.04 to 4.59 CFU/g were found over the periods of depuration (Fig. 2C). The total viable cell counts in oysters were found almost similar to the MPN results of $V$. vulnificus during the depuration. These results strongly suggest that no cross-contamination has occurred during depuration, which indicates that UV-irradiation effectively sterilized the water supply for the depuration in the tank system (Sorio et al., 2017). According to the present study, results show that live bioaccumulated oysters were continuously depurated in the circulation-tank. This tank has a continuous circulation system and this circulation process includes a sterilization process using UV-light. Therefore, $V$. vulnificus contaminated artificial seawater is effectively sterilized by UV-lights, and the sterilized artificial seawater is continuously provided to the live oysters. In addition, oysters have characteristics of the filter-feeder, which influences the reducing cell population of bioaccumulated $V$. vulnificus in the oyster.

\section{Changes in oyster freshness factors $(\mathrm{pH}$ and glycogen) during depuration}

Various complex factors such as physiological, individual differences, seawater turbidity, salinity, $\mathrm{pH}$, temperature, immersion depth, and dissolved oxygen level are all influential during the depuration process of shellfish (Lees et al., 2010). Besides, according to Otwell et al. (2018), the depuration process also tends to decrease the qualities of 
oysters due to the impact of stress forces on the shellfish. Hence, the present study also investigated the effect of depuration on the quality of oysters, especially freshness factors such as $\mathrm{pH}$ and glycogen. $\mathrm{pH}$ is an essential factor used as an indicator to determine the freshness of oysters (Pottinger et al., 1948). Oysters contain a high amount of glycogen that undergoes glycolysis and results in lactate production that may decrease the $\mathrm{pH}$ after harvesting and during the time of storage and distribution (Cao et al., 2009; Park et al., 2006). As shown in Fig. 3A, no significant $\mathrm{pH}$ changes were observed in the bioaccumulated (6.51-6.62) and non-bioaccumulated (6.47-6.66) oyster samples during the depuration. Thus the $\mathrm{pH}$ level of the oysters was found to be constant regardless of the bioaccumulation and depuration process of $V$. vulnificus. According to the previous study, the $\mathrm{pH}$ range of fresh oysters was found in the range of 6.3-6.5 (Jeong et al., 2015; Son et al., 2014). It has also been reported that the $\mathrm{pH}$ level of the oyster can qualify its freshness such as; 6.3 or higher was "Very good," 6.2-5.9 was "good," 5.8 was "off," 5.7-5.5 was "musty," and 5.2 or less was judged as "sour" or "putrid" (Pottinger et al., 1948; Son et al., 2014). Considering the above results, it is concluded that the freshness of oysters in the present study was not affected by the bioaccumulation and depuration process.

As described above, glycogen is the most abundant carbohydrate in oysters and is considered another important factor in determining the freshness and food quality of oysters (Son et al., 2014). Hence, during the depuration process, the changes in glycogen contents were also determined. As shown in Fig. 3B, no significant changes in glycogen content were observed in both bioaccumulated $(1.08-1.12 \mathrm{~g} / 100 \mathrm{~g})$ and non-bioaccumulated (1.08-1.09 g/100 g) oyster during the depuration process. Thus, no changes in glycogen content were found to be similar to the no change of $\mathrm{pH}$ levels in the oysters during the depuration process, as expected. These results were consistent with the previous report which described that the depuration process did not affect the glycogen content of oysters (Huntley et al., 1971). These results strongly suggested that the bioaccumulation of $V$. vulnificus to the oysters and the depuration process do not affect the freshness and quality of oysters.

In conclusion, the present study showed the development of $V$. vulnificus bioaccumulated shellfish model using alive oysters. The bioaccumulated live oysters were depurated in an HDPE-tank equipped with UV-irradiation. A significant cell number of $V$. vulnificus in oysters was found to reduce during the depuration process, which satisfied the reduction point of depuration efficiency suggested by the NSSP guideline. Furthermore, no significant changes in $\mathrm{pH}$ and glycogen contents were observed, indicating that the freshness and quality of the oyster were
(A)

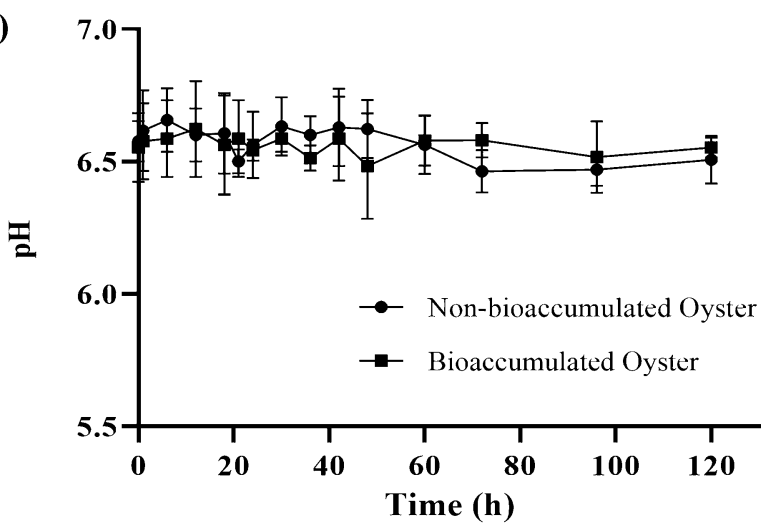

(B)

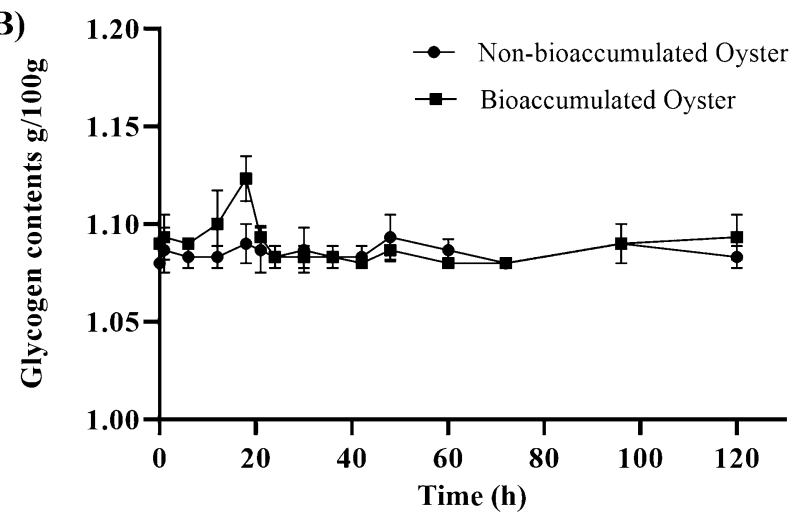

Fig. 3 Changes in quality indicator (glycogen contents and $\mathrm{pH}$ ) of bioaccumulated oysters during the depuration period. (A) Changes in $\mathrm{pH}$ value of the oyster during depuration (B) Changes in glycogen contents $(\mathrm{g} / 100 \mathrm{~g})$ during depuration

unaffected during the depuration process. These results strongly suggest that the depuration process using UV-irradiation is very useful to purify oysters that have been bioaccumulated or contaminated by $V$. vulnificus without losing its freshness and quality. This finding may also contribute to developing a shellfish purification system that considers the effects of environmental factors such as temperature, salinity, and $\mathrm{pH}$.

Acknowledgement This research was a part of the project titled 'Development of on-site diagnosis system for microbiological hazards in the fishery environment (20200377-2)', funded by the Ministry of Oceans and Fisheries, Korea.

Author contributions $\mathrm{YK}$ designed the experiment and analyzed data. HJ, SKP, DJ, JHL, MGK, FK, DL, and YAS experimented HJ, SKP, FK, and YK drafted the manuscript.

\section{Declarations}

Conflict of interest The authors declare that they have no conflict of interest. 


\section{References}

Ashrae. ASHRAE Handbook 2016: HVAC Systems and Equipment, SI Edition, Chapter 17, 22 (2016)

Cao R, C H Xue, Q Liu, Y Xue. Microbiological, chemical, and sensory assessment of Pacific oysters (Crassostrea gigas) stored at different temperatures. Czech Journal of Food Sciences, 27: 102-108 (2009)

Chae M, D Cheney, Y Su. Temperature effects on the depuration of Vibrio parahaemolyticus and Vibrio vulnificus from the American oyster (Crassostrea virginica). Journal of Food Sciences, 74: 62-66 (2009)

Cicik B, and K Engin. The effects of cadmium on levels of glucose in serum and glycogen reserves in the liver and muscle tissues of Cyprinus carpio. Turkish Journal of Veterinary and Animal Sciences, 29: 113-117. (2005)

Copat C, Arena G, Fiore M, Ledda C, Fallico R, Sciacca S, Ferrante M. Heavy metals concentrations in fish and shellfish from eastern Mediterranean Sea: consumption advisories. Food and Chemical Toxicology, 53: 33-37 (2013)

Croci L, Suffredini E, Cozzi L, Toti L. Effects of depuration of molluscs experimentally contaminated with Escherichia coli, Vibrio cholerae $\mathrm{O} 1$ and Vibrio parahaemolyticus. Journal of Applied Microbiology, 92: 460-465 (2002)

de Abreu Corrêa A, Albarnaz J D, Moresco V, Poli C R, Teixeira A L, Simoes C M O, Barardi C R M. Depuration dynamics of oysters (Crassostrea gigas) artificially contaminated by Salmonella enterica serovar Typhimurium. Marine Environmental Research, 63: 479-489 (2007)

Dore W J, Lees D N. Duncan D B. Multiple-range and multiple F-tests. Biometrics 11: 1-42 (1955)

Horseman M A, Surani S. A comprehensive review of Vibrio vulnificus: an important cause of severe sepsis and skin and softtissue infection. International Journal of Infectious Diseases, 15: e157-e166 (2011)

Huntley B E, Hammerstrom R J. An experimental depuration plant: operation and evaluation. Chesapeake Science 12: 231-239 (1971)

Jang Y M, Park S K, Jeong H J, Lee J W, Yoon Y H, Park K S, Shin I S, Kim Y M. Quantitative ell count of Vibrio vulnificus cells based on MPN-PCR method. Journal of Food Hygiene and Safety, 33: 412-415 (2018)

Jeong E T, Han H N, Kim Y H, Lee E H, Kim D H, Kim J H, Yeom S M, Kim Y M. The effects of natural food additives on the selflife and sensory properties of shucked and packed Pacific oyster Crassostrea gigas. Korean Journal of Fisheries and Aquatic Sciences, 48: 244-248 (2015)

Kwon J Y, Song K C, Son K T, Yu H, Kim P H, Shin S B, Mok J S, Lee K J, Oh E G, Yoon H D, Lim K S, Kim Y M. Development of a proficiency test specimen for enumerating Escherichia coli in molluscan bivalve shellfish. Fisheries and Aquatic Sciences, 14: 226-229 (2011)

Lee R, Lovatelli A, Ababouch L. Bivalve depuration: Fundamental and practical aspects. FAO Fisheries Technical Paper 511: 5-50 (2008)

Lees D. Viruses and bivalve shellfish. International Journal of Food Microbiology, 59: 81-116 (2000)

Lees D, Younger A, Dore B Depuration and Relaying. Safe Management of Shellfish and Harvest Waters 146-176 (2010)

Luan X, Chen J, Liu Y, Li Y, Jia J, Liu R, Zhang X H. Rapid quantitative detection of Vibrio parahaemolyticus in seafood by MPN-PCR. Current Microbiology, 57: 218-221 (2008)

McLeod C, Polo D, Le Saux J-C, Le Guyader F S. Evaluating the effectiveness of depuration in removing norovirus from oysters.
Seafood Safety Assessment Ltd. French Research Institute for Exploitation of the Sea, 9-66 (2017)

National Shellfish Sanitation Program (NSSP). Recognized by U. S. Food and Drug Administration. Guide for the Control of Molluscan Shellfish. Available on: https://www.fda.gov/food/ federalstate-food-programs/national-shellfish-sanitation-pro gram-nssp accessed at November 10, 2019

Oh E G, Yoo H D, Yu H S, Ha K S, Shin S B, Lee T S, Lee H J, Kim J $\mathrm{H}$, Son K T. Removal of fecal indicator bacteria from bivalves under natural and electrolyzed water. Korean Journal of Fisheries and Aquatic Sciences, 45: 11-16 (2012)

Oliveira J, Cunha A, Castilho F, Romalde J L, Pereira M J. Microbial contamination and purification of bivalve shellfish: Crucial aspects in monitoring and future perspectives-A mini-review. Food Control, 22 :805-816 (2011)

Otwell W S. Molluscan shellfish depuration. CRC Press (2018)

Panicker G, Call D R, Krug M J, Bej A K. Detection of pathogenic Vibrio spp. in shellfish by using multiplex PCR and DNA microarrays. Applied and Environmental Microbiology, 70: 7436-7444 (2004)

Park W J, Jwa M K, Hyun S H, Lim S B, Song D J. Microbial and quality changes during storage of raw oyster treated with high hydrostatic pressure. Journal of the Korean Society of Food Science and Nutrition, 35: 1449-1455 (2006)

Phuvasate S, Chen M H, Su Y C. Reductions of Vibrio parahaemolyticus in Pacific oysters (Crassostrea gigas) by depuration at various temperatures. Food Microbiology. 31: 51-56 (2012)

Pottinger S R. Some data on $\mathrm{pH}$ and the freshness of shucked eastern oysters. Comm. Fisheries Rev 10: 1-3 (1948).

Ramos R J, Miotto M, Squella F J L, Cirolini A, Ferreira J F, Vieira C $\mathrm{R}$ W. Depuration of oysters (Crassostrea gigas) contaminated with Vibrio parahaemolyticus and Vibrio vulnificus with UV light and chlorinated seawater. Journal of Food Protection, 75: 1501-1506 (2012)

Son K T, Shim K B, Lim C W, Yoon N A, Seo J H, Jeong S G, Jeong W Y, Cho Y J. Relationship of $\mathrm{pH}$, glycogen, soluble protein, and turbidity between freshness of raw oyster Crassostrea gigas. Korean Journal of Fisheries and Aquatic Sciences, 47: 495-500 (2014)

Sorio J C, Peralta J P. Evaluation of a small scale UV-treated recirculating depuration system for oysters (Crassostrea iredalei). American Journal of Food Science and Technology, 5: 117-124 (2017)

Tauxe R V. Emerging foodborne diseases: An evolving public health challenge. Emerging Infectious Diseases Journal, 3: 425-434 (1997)

Thupila N, Ratana-Arporn P, Wilaipun P. Radiation resistances and decontamination of common pathogenic bacteria contaminated in white scar oyster (Crassostrea belcheri) in Thailand. Radiation Physics and Chemistry, 80: 828-832 (2011)

U. S. Food and Drug Administration (U.S. FDA). Bacteriological analytical manual (BAM). 8th Ed. Revision A. Available on: https://www.fda.gov/food/laboratory-methods-food/bacteriologi cal-analytical-manual-bam accessed at November 10, 2019

Wang H Y, Lee G H. Rapid identification of Vibrio vulnificus in seawater by real-time quantitative TaqMan PCR. Journal of Microbiology, 41: 320-326 (2003)

Publisher's Note Springer Nature remains neutral with regard to jurisdictional claims in published maps and institutional affiliations. 